\title{
Leverage Effect In Chinese And American Index Returns
}

Ma Carmen García-Centeno, Ph.D., CEU San Pablo University, Spain Román Mínguez, Ph.D., University of Castilla-La Mancha, Spain

\begin{abstract}
A lot of changes have happened in the Chinese economy in the last three decades. To study whether these changes affect the symmetric or asymmetric behavior of the volatility in Chinese Stock Market, in this paper we analyze, first, the main stylized facts in similar Chinese and American index returns and, second, we compare the leverage effect of volatility in three different periods for these indexes.
\end{abstract}

The estimated results with GJR-GARCH and TA-ARSV models have shown that the behaviour of Chinese index returns was different depending on whether China was part of the Trade World Trade Organization (WTO).

Keywords: Leverage Effect; Stochastic Volatility; Stock Returns

\section{INTRODUCTION}

$\varnothing \mathrm{n}$ the last decades, political and economic reforms have taken place in China primarily because it was a closed and centralized economy and nowadays is one of the strongest economies in the world. These reforms have allowed the transition between communism and capitalism and, furthermore, changes have occurred in a gradual form in order to get macroeconomic stabilization, trade liberalization and financial openness and to avoid getting into hyperinflation, erosion of wages and depressed demand, Brandt and Zhu (2000), Rao (2004), Pan and Zhang (2006).

The evolution of financial system and stock market has been one of the most important points for these changes, Serrano (2002), Chow (2007). That is the reason why in this paper we try, on the one hand, to analyze the main stylized facts in some Chinese stock index returns and, on the other hand, to study if there is an asymmetric behaviour of volatility in this market during the different stages that China has spent on this process of opening.

To estimate the dynamic of the volatility we use two different asymmetric models: the GJR-GARCH with t-Student distribution, Glosten et al. (1993) and TA-ARSV proposed by So et al (2002) and developed by García and Mínguez (2009).

The remainder of the paper is organized as follows. Section 2 analyzes the main stylized facts of the different studied indexes. Section 3 defines the GJR-GARCH and TA-ARSV models. Section 4 shows the main results and section 5 provides some concluding remarks.

\section{CHARACTERISTIC OF CHINESE AND AMERICAN STOCK INDEXES RETURNS.}

To analyze the main stylized facts of the returns, we have used some Chinese price indexes ${ }^{1}$ : Shanghai SE Composite (denoted by CHSCOMP) and the Shenzhen SE Composite (denoted by CHZCOMP). Sample period of these data is from 02/01/1991 to 18/05/2011 and 01/01/1991 to 18/05/2011 respectively. These two indexes are the most widely used indicators of China's equity market. To compare the results with the American Stock indexes, we

\footnotetext{
${ }^{1}$ All information of these indexes has been obtained from DataStream Data Base. 
have used the following indexes: S\&P industrial price index (denoted by S\&PINDS) and S\&P 500 Composite price index (denoted by S\&PCOMP) in the sample period from 01/01/1990 to 18/05/2011.

For all the different indexes we consider the daily closing data. In all cases, the sample size is greater than 5000 observations. Returns $\left(\mathrm{Y}_{\mathrm{t}}\right)$ are defined as the first difference of natural logarithm of price indexes in two consecutive days of market, that is,

$Y_{t}=100 *\left(\log p_{t}-\log p_{t-1}\right), \quad$ w here, $\mathrm{p}_{\mathrm{t}}$ is price of index at day $\mathrm{t}$.

The descriptive statistics calculated in Table 1 show that the mean is statistically zero in all time series. The standard deviation is bigger in Chinese than American returns. All series exhibit an excess kurtosis (the returns are leptokurtic) and American indexes are negatively skewed while Chinese indexes are positively skewed, indicating that the returns are not normally distributed. The Jarque-Bera normality tests show the rejection of normality for all the returns with significance level of 5\%, therefore we choose a t-Student distribution in the estimation process. The Ljüng Box Q-statistics, both for the returns and squared returns, are listed in the last row. In conclusion, the level returns for American indexes have significant correlations, gathered with a $\operatorname{ARMA}(0,1)$ model, but we accept the null hypothesis of white noise for Chinese level returns. However, we always reject the null hypothesis for squared returns.

Table 1. Summary Statistics.

\begin{tabular}{|l|c|c|c|c|}
\hline & S\&PINDS & S\&PCOMP & CHSCOMP & CHZCOMP \\
\hline N & 5577 & 5577 & 5315 & 5250 \\
\hline Minimum & -9.49 & -9.46 & -17.90 & -23.36 \\
\hline Maximum & 11.194 & 10.957 & 71.915 & 27.215 \\
\hline Mean & 0.026 & 0.023 & 0.058 & 0.047 \\
\hline Standard Deviation & 1.1138 & 1.1452 & 2.4658 & 2.2976 \\
\hline Variation Coefficient & 42.03 & 47.91 & 42.22 & 48.49 \\
\hline Excess Kurtosis & 8.7012 & 9.3170 & 149.17 & 16.047 \\
\hline Skewness & -0.1323 & -0.2037 & 5.5605 & 0.60618 \\
\hline Normality Test & $4689.6^{* *}$ & $5055.4^{* *}$ & $18490^{* *}$ & $8363^{* *}$ \\
\hline$Q_{y_{t}}(20)$ & $71.6^{* *}$ & $76.4^{* *}$ & 33.1 & 28.9 \\
\hline$Q_{y_{t}^{2}}(20)$ & $6429.6^{* *}$ & $7363.5^{* *}$ & $314.53 * *$ & $869.86^{* *}$ \\
\hline
\end{tabular}

** Significant at the 0.05 significance level. Normality test (Jarque-Bera).

Statistically zero mean in all time series.

The evolution of stock index returns, Figure 1, shows that the returns have a constant mean but the variance is not constant because there are some periods with high volatility and others with lower volatility, that is, there are volatility clusters. The periods with highest volatility correspond to the beginning and end of nineties and, also, the period covered by the current financial crisis that began in 2008.

The autocorrelation function estimated (ACF) for squared returns shows that the estimated correlations are statistically significant. These correlations are higher in the American than Chinese returns. All correlations for the American squared returns are positive (especially because the existence of volatility clusters) and decrease slowly to zero, which implies persistence in volatility, see Figure 2. As a consequence, although the returns are uncorrelated, they are not independent because non-linear transformations of them are positively correlated. 

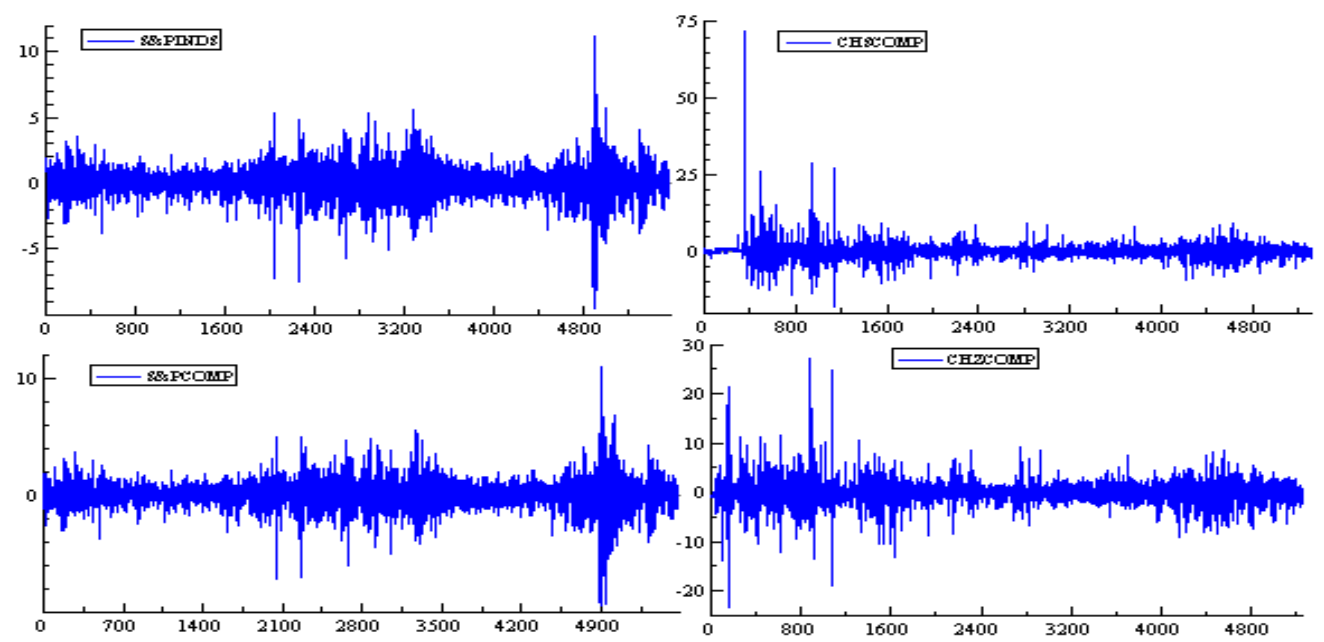

Figure 1. Evolution of Chinese and American stock index returns in the sample period analyzed

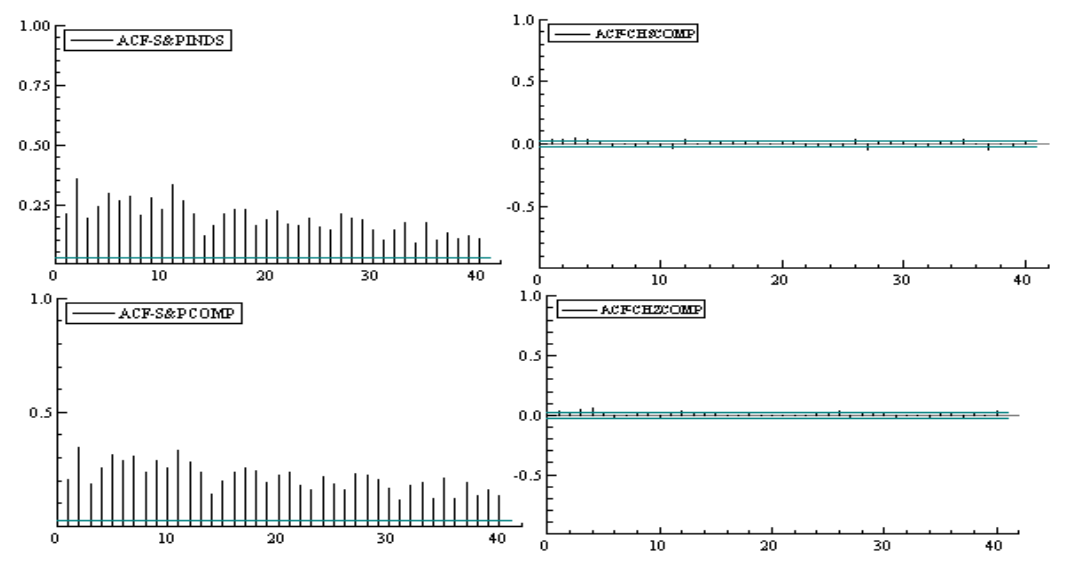

Figure 2. Autocorrelation Function (ACF) for Chinese and American squared returns

\section{GJR-GARCH AND TA-ARSV MODELS}

After examining the main stylized facts, we propose two models to describe the dynamic of volatility and estimate their symmetric or asymmetric behaviour: GJR-GARCH and TA-ARSV. The equations describing GJRGARCH(1,1) model are:

$$
\begin{aligned}
& Y_{t}=\sigma_{t} \varepsilon_{t} \\
& \sigma_{t}^{2}=\varpi+\alpha \varepsilon_{t-1}^{2}+\gamma S_{t-1}^{-} \varepsilon_{t-1}^{2}+\beta \sigma_{t-1}^{2}
\end{aligned}
$$

where $Y_{t}$ are the returns; $\sigma_{t}^{2}$ is the volatility and $\varepsilon_{t}$ is a random disturbance that, for the American returns, follows an $\operatorname{ARMA}(0,1)$ process, such as, $\varepsilon_{t}=a_{t}+\psi a_{t-1}$ where $a_{t}$ is a white noise with zero mean and unit variance. On the contrary, for the Chinese returns $\varepsilon_{t}$ is a white noise. In both cases, $S_{t-1}^{-}$is a dummy variable with unit value when returns are negative and $\gamma$ is a parameter that determines the asymmetric behavior of volatility. If $\gamma=0$ there is not leverage effect but, on the other hand, if $\gamma>0$, volatility is higher when there are bad news $(\alpha+\gamma)$ than good news $(\alpha)$ in the market. 
The equations describing TA-ARSV(1) model are:

$Y_{t}=\sigma_{*} \exp \left(0.5 h_{t}\right) \varepsilon_{t}$

$\log \left(\sigma_{t}^{2}\right)=h_{t}=\left(\phi_{11} I_{1 t}+\phi_{12} I_{2 t}\right) h_{t-1}+\eta_{t}$

where, $\sigma_{*}$ is a positive scale factor in the mean equation, included to avoid the need to add a constant in the logvolatility equation and, eventually, $h_{t}$ is the log-volatility. Equation (4) indicates that log-volatility follows an AR(1) process in each regime, moreover, $\eta_{t}$ is a white noise process in log-volatility equation and follows a Normal distribution with zero-mean and variance $\sigma_{\eta}^{2}$. The distribution of $\varepsilon_{t}$ and $\eta_{t}$ is independent $\forall t, s$ and $\phi_{11}$ is a parameter that measures the effect of positive returns in volatility and $\phi_{12}$ measures the effect in volatility of negative returns. Finally, $I_{l t}$ and $I_{2 \mathrm{t}}$ are two indicator variables, which are defined as follows:

$I_{1, t}=\left\{\begin{array}{l}1 \forall t \text { when the index return is positive or zero } \\ 0 \text { in all other cases }\end{array} I_{2, t}=\left\{\begin{array}{l}1 \forall t \text { when the index return is negative } \\ 0 \text { in all other cases }\end{array}\right.\right.$

It is important to realize that, if the parameters $\phi_{11}$ and $\phi_{12}$ are statistically different, this implies an asymmetric behavior in volatility, but, if both parameters are statistically equal, then the volatility is symmetric and the model to explain the dynamic of volatility should be an ARSV(1) model.

\section{ESTIMATED RESULTS OF GJR-GARCH(1,1) AND TA-ARSV(1) MODELS}

To analyze the asymmetric behaviour of volatility we have divided the sample period in three sub-periods: the first one, from the beginning to 2000 (the opening of China under WTO); second one, from 2001 to 2005 (the established transition period in agreement WTO ends) and third one, from 2006-2011. The estimated results for GJR-GARCH(1,1) model are in Table 2 and for TA-ARSV(1) and ARSV(1) model are in Table 3.

Table 2. Estimated Results for ARMA(0,1)_GARCH(1,1) model with t-Student Distribution

\begin{tabular}{|c|c|c|c|c|c|c|c|c|}
\hline & & $\varnothing$ & $\alpha$ & $\boldsymbol{\beta}$ & $\gamma$ & $\begin{array}{c}\text { Leverage } \\
\text { Effect }\end{array}$ & $\begin{array}{c}\text { Student } \\
\text { (DF) }\end{array}$ & Persistence \\
\hline \multirow{4}{*}{ 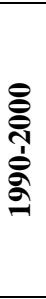 } & S\&PINDS & $\begin{array}{c}0.018 \\
(0.017) \\
\end{array}$ & $\begin{array}{c}0.007 \\
(0.003) \\
\end{array}$ & $\begin{array}{c}0.938 \\
(0.013)\end{array}$ & $\begin{array}{c}0.095 \\
(0.025) \\
\end{array}$ & Yes & $\begin{array}{c}6.222 \\
(0.730) \\
\end{array}$ & 0.993 \\
\hline & S\&PCOMP & $\begin{array}{c}0.025 \\
(0.017) \\
\end{array}$ & $\begin{array}{c}0.005 \\
(0.005) \\
\end{array}$ & $\begin{array}{c}0.938 \\
(0.012) \\
\end{array}$ & $\begin{array}{c}0.100 \\
(0.024) \\
\end{array}$ & Yes & $\begin{array}{c}6.296 \\
(0.756) \\
\end{array}$ & 0.993 \\
\hline & CHSCOMP & & $\begin{array}{c}0.400 \\
(0.081)\end{array}$ & $\begin{array}{c}0.706 \\
(0.029)\end{array}$ & $\begin{array}{c}0.144 \\
(0.157)\end{array}$ & No & $\begin{array}{c}3.113 \\
(0.241)\end{array}$ & 1.178 \\
\hline & CHZCOMP & & $\begin{array}{c}0.418 \\
(0.077)\end{array}$ & $\begin{array}{c}0.111 \\
(0.066)\end{array}$ & $\begin{array}{c}0.111 \\
(0.066)\end{array}$ & No & $\begin{array}{c}3.176 \\
(0.249)\end{array}$ & 1.151 \\
\hline \multirow{4}{*}{ 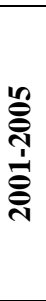 } & S\&PINDS & $\begin{array}{c}-0.061 \\
(0.028) \\
\end{array}$ & $\begin{array}{c}-0.012 \\
(0.007) \\
\end{array}$ & $\begin{array}{c}0.958 \\
(0.012) \\
\end{array}$ & $\begin{array}{c}0.095 \\
(0.020) \\
\end{array}$ & Yes & $\begin{array}{c}26.912 \\
(14.912) \\
\end{array}$ & 0.993 \\
\hline & S\&PCOMP & $\begin{array}{l}-0.057 \\
(0.027)\end{array}$ & $\begin{array}{l}-0.016 \\
(0.008)\end{array}$ & $\begin{array}{c}0.954 \\
(0.012)\end{array}$ & $\begin{array}{c}0.109 \\
(0.022)\end{array}$ & Yes & $\begin{array}{c}27.657 \\
(22.173) \\
\end{array}$ & 0.992 \\
\hline & CHSCOMP & & $\begin{array}{c}0.064 \\
(0.040)\end{array}$ & $\begin{array}{c}0.731 \\
(0.079)\end{array}$ & $\begin{array}{c}0.229 \\
(0.085)\end{array}$ & Yes & $\begin{array}{c}3.569 \\
(0.472)\end{array}$ & 0.911 \\
\hline & CHZCOMP & & $\begin{array}{c}0.088 \\
(0.056) \\
\end{array}$ & $\begin{array}{c}0.743 \\
(0.132) \\
\end{array}$ & $\begin{array}{c}0.190 \\
(0.095) \\
\end{array}$ & Yes & $\begin{array}{c}4.081 \\
(0.613) \\
\end{array}$ & 0.927 \\
\hline \multirow{4}{*}{ 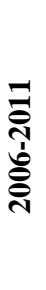 } & S\&PINDS & $\begin{array}{l}-0.060 \\
(0.024)\end{array}$ & $\begin{array}{l}-0.039 \\
(0.012)\end{array}$ & $\begin{array}{c}0.925 \\
(0.019)\end{array}$ & $\begin{array}{c}0.202 \\
(0.036)\end{array}$ & Yes & $\begin{array}{c}4.734 \\
(0.745) \\
\end{array}$ & 0.987 \\
\hline & S\&PCOMP & $\begin{array}{l}-0.069 \\
(0.024) \\
\end{array}$ & $\begin{array}{c}-0.028 \\
(0.012) \\
\end{array}$ & $\begin{array}{c}0.928 \\
(0.017) \\
\end{array}$ & $\begin{array}{c}0.186 \\
(0.034) \\
\end{array}$ & Yes & $\begin{array}{c}4.434 \\
(0.656) \\
\end{array}$ & 0.993 \\
\hline & CHSCOMP & & $\begin{array}{c}0.085 \\
(0.019)\end{array}$ & $\begin{array}{c}0.917 \\
(0.023)\end{array}$ & $\begin{array}{c}0.101 \\
(0.034)\end{array}$ & Yes & $\begin{array}{c}3.778 \\
(0.451)\end{array}$ & 1.003 \\
\hline & CHZCOMP & & $\begin{array}{c}0.113 \\
(0.030)\end{array}$ & $\begin{array}{c}0.881 \\
(0.037)\end{array}$ & $\begin{array}{c}0.109 \\
(0.036)\end{array}$ & Yes & $\begin{array}{c}3.875 \\
(0.459)\end{array}$ & 0.999 \\
\hline
\end{tabular}


Table 3. Estimated Results for TA-ARSV(1) and ARSV(1) models

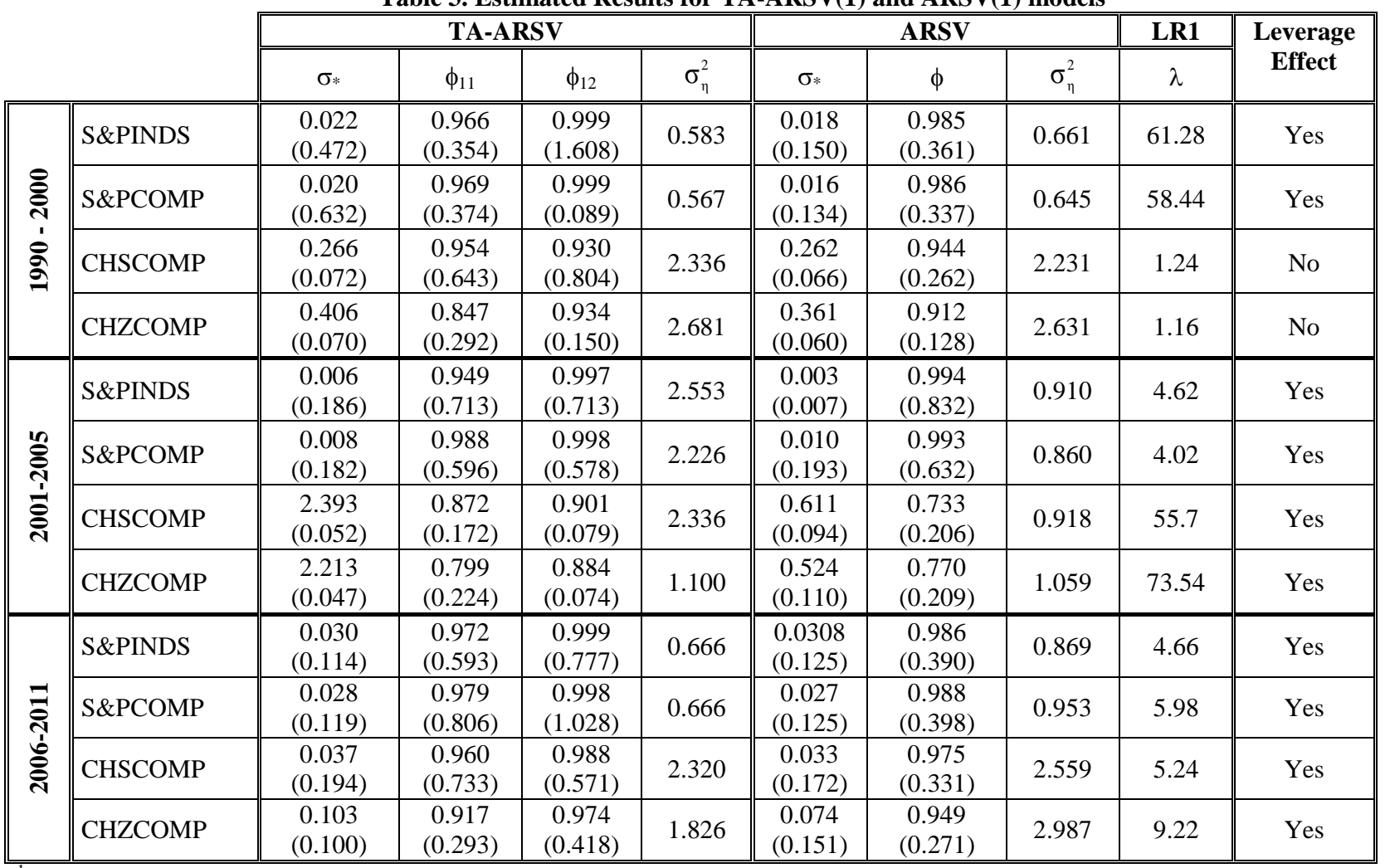

${ }^{1}$ Likelihood Ratio Contrast (LR). Critical value: 3.84 (5\%).

The value between parenthesis for $\sigma_{*}, \phi_{11}, \phi_{12}$ and $\phi$ is the standard error.

The obtained results in Table 2 show that before 2001, there is not leverage effect in Chinese index returns. However, all American and Chinese index returns have an asymmetric behavior in the rest of periods. This asymmetric behavior is higher for bad than for good news in the market, because the parameter $\gamma$ is positive in all cases. The estimated persistence is quite high for all periods and indexes, but in some cases it is greater than one, which implies that the process is nonstationary.

The estimated results with TA-ARSV(1) model confirm that there is no an asymmetric behaviour in volatility for Chinese index returns before 2001, because LR contrast does not reject the null hypothesis $\left(\mathrm{H}_{\mathrm{o}}: \phi_{11}=\phi_{12}\right)$. In the rest of periods and index returns, the volatility is higher in a $t$ period when in $t-1$ period the returns are negative, because LR contrast rejects the null hypothesis and $\phi_{12}$ is always greater than $\phi_{11}$ parameter. In each regime, the persistence is measured with the $\phi_{11}$ and $\phi_{12}$ parameters. Both of them are always lower than one, as for American as for Chinese index returns, which implies that the estimated process is stationary in all cases, and, moreover, the persistence is also uniformly lower than the persistence estimated with GJR-GARCH(1,1) model.

\section{CONCLUDING REMARKS}

This paper has investigated if the volatility in Chinese index returns, before and after China was part of WTO, has leverage effect. Furthermore, the results have been compared with the results of American index returns during the studied sample period. The estimations with GJR-GARCH(1,1) and TA-ARSV(1) models reflect that, before 2001, there is not a leverage effect in Chinese index returns.

For the periods when we have detected the existence of leverage effect, the impact in volatility of bad news is uniformly greater than the impact of good news for all indexes. 
Finally, the estimated persistence is high for all models (close to one in all cases) but estimations with GJRGARCH $(1,1)$ models are, sometimes, not stationary in covariance. Nevertheless, the persistence estimated with TAARSV(1) models always correspond to stationary models.

\section{AUTHOR INFORMATION}

María del Carmen García-Centeno, Ph.D. in Economics by CEU San Pablo University and Degree in Economics by University Complutense of Madrid. Lecturer in Statistics at Quantitative Methods Department. Faculty of Business and Economics. CEU San Pablo University. Madrid (Spain). Research Interest: Stochastic volatility, time series analysis, regional analysis. E-mail: garcen@ceu.es

Román Mínguez-Salido, Ph.D. in Economics by CEU San Pablo University and Degree in Economics by University Complutense of Madrid. Msc in Mathematical Engineering by University Complutense of Madrid. Lecturer in Statistics at Statistics Department. Faculty of Social Sciences of Cuenca. University of Castilla-La Mancha (Spain). Research Interest: Spatial econometrics, regional analysis, time series analysis. E-mail: Roman.Minguez@uclm.es (Corresponding author)

\section{REFERENCES}

1. Brandt and Zhu (2000). "Redistribution in a Decentralized Economy: Growth and Inflation in China under Reform". Journal of Political Economy 108:2, pp. 422-451.

2. Chow, G. (2007). “China's economic transformation", Second Edition, Blackwell publications.

3. García-Centeno, M.C. and Minguez-Salido, R. (2009). "Estimation of Asymmetric Stochastic Volatility Models for Stock Exchange Index Returns". International Advances in Economic Research, 15, pp 71-87.

4. Glosten, L., Hagannathan, R. and Runkle, D. (1993). "The relation between the expected value and the volatility of the nominal excess return on stocks". Journal of finance, 48, pp. 1779-1801.

5. Pan, H. and Zhang, Z. (2006). "Forecasting financial volatility: Evidence from Chinese Stock Market". Working paper in Economics and Finance 06/02. University of Durham (UK).

6. Rao, N.J. (2004). "Chinese Economy: Issues and Perspectives". ICFAI University Press, 2004 (Asia Programme Working Paper, $\mathrm{n}^{\circ}$ 1). The Royal Institute of International Affairs, London (UK).

7. Serrado, J. (2002). "China's entry to the WTO and the financial sector". Banco Sabadell Publications.

8. So, M.K.P., Li, W.K. and Lam, K. (2002). "A threshold stochastic volatility model”. Journal of Forecasting, 21, pp. 473-500. 